\title{
Correction to: Quality of care evaluation in non-functioning pituitary adenoma with chiasm compression: visual outcomes and timing of intervention clinical recommendations based on a systematic literature review and cohort study
}

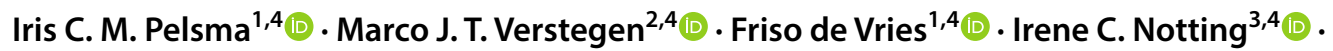

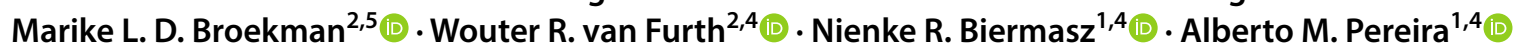

Published online: 21 June 2020

(c) The Author(s) 2020

\section{Correction to: Pituitary}

https://doi.org/10.1007/s11102-020-01044-0

The original version of the article unfortunately contained an error in Fig. 2. The term 'Refer within 3 days' should read 'Refer as soon as possible'. Corrected version of Fig. 2 is given below.

The original article can be found online at https://doi.org/10.1007/ s11102-020-01044-0.

Iris C. M. Pelsma

I.C.M.Pelsma@lumc.nl

1 Division of Endocrinology, Department of Medicine, Leiden University Medical Center, Albinusdreef 2, 2333 ZA Leiden, The Netherlands

2 Department of Neurosurgery, Leiden University Medical Center, Leiden, The Netherlands

3 Department of Ophthalmology, Leiden University Medical Center, Leiden, The Netherlands

4 Center for Endocrine Tumors Leiden, Leiden University Medical Center, Leiden, The Netherlands

5 Department of Neurosurgery, Haaglanden Medical Center, Den Haag, The Netherlands 


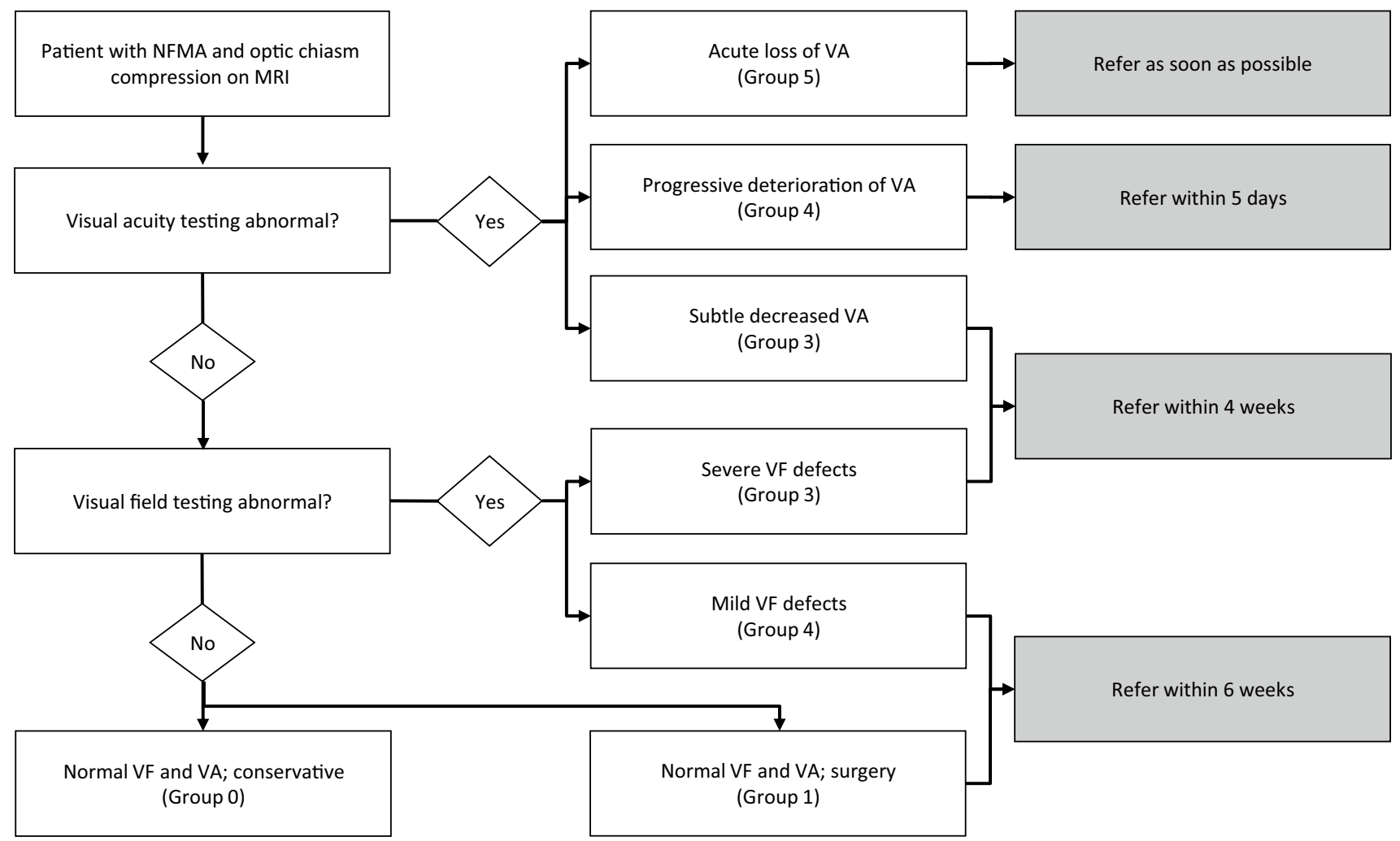

Fig. 2 Flowchart of proposed referral delays depending on visual function and compression of optic chiasm. Proposed time(frames) for

field defects from a non-expertise to an expertise center. $V A$ visual the referral of NFMA patients with visual acuity impairment or visual acuity, $V F$ visual field

Publisher's Note Springer Nature remains neutral with regard to jurisdictional claims in published maps and institutional affiliations. 